\title{
A Fronteira entre Trabalho e Emprego: notas sobre atividades paralelas no Pampa Gaúcho
}

\author{
Letícia de Faria Ferreira \\ Universidade Federal da Fronteira Sul, Santa Catarina, Brasil \\ E-mail: leticiadefaria@hotmail.com

\section{Jussemar Weiss Gonçalves} \\ Universidade Federal do Rio Grande, Rio Grande do Sul, Brasil \\ E-mail: jussweiss@hotmail.com
}




\section{Resumo}

Este artigo apresenta algumas notas etnográficas sobre os significados das atividades paralelas ao emprego formal para a população de uma pequena cidade pampeana. A pesquisa apresenta arranjos realizados pelos trabalhadores para manter o equilíbrio entre atividades assalariadas urbanas e atividades rurais, cujas definições nativas podem variar desde atividades paralelas, independentes ou até mesmo prazerosas. Ao considerar as trajetórias de vida de uma parcela dos trabalhadores urbanos, observa-se que a origem rural é muito próxima: ou eles são recém-chegados ao meio urbano, ou são seus pais e avós que têm um passado vivido no meio rural. A memória dessa existência dificilmente se dissolve plenamente mediante as novas experiências urbanas, pelo contrário, o que se pode observar é a incidência e a ressignificação dos costumes rurais para o cotidiano urbano. A percepção que cada trabalhador narra dessa experiência do trabalho rural paralelo ao emprego assalariado urbano é o que se busca descrever.

Palavras-chave: Emprego Assalariado/ Atividade Rural. Memória. Cultura e Trabalho.

\section{Abstract}

This article aims to present some ethnographic notes on the meanings the activities which are parallel to formal employment assume for the population of a small town at the pampa. The research indicates the arrangements of the workers in order to maintain a balance between urban employment and rural activities, whose native definition may vary among parallel, independent or even pleasant activities. When considering the life trajectories of a portion of the urban workers, we can observe that the rural origin is very close: or they are newcomers to the urban environment, or their parents or grandparents have a past lived in rural areas. The memory of that existence hardly dissolves fully in touch with the new urban experiences, on the contrary, what we see is the incidence the ressignification of rural customs to daily urban life. The perception that each worker tells about the experience of rural work parallel to urban wage employment is what we intend to describe.

Keywords: Wage Employment/Rural Activity. Memory. Culture and Work. 
"O Campeador é no homem força maior do que ele"

(Carlos Nejar)

\section{Introdução}

Z ste artigo discorre sobre as relações profissionais - de trabalho Lassalariado - e as outras atividades e ofícios praticados por pequenos proprietários rurais da região do pampa. O objetivo é descrever como trabalhadores urbanos mantêm outra atividade no meio rural, sendo esta última bastante complexa e de acepção plural, pois ela é permeada por significados que não necessariamente correspondem às definições clássicas de trabalho, rendimento econômico ou mesmo produção agrícola. A percepção que cada trabalhador narra dessa experiência do trabalho rural paralelo ao emprego assalariado urbano é o que se busca descrever.

Este artigo é parte do resultado de uma pesquisa, que tenta, basicamente, destacar os arranjos e as possibilidades de equilíbrio entre as atividades assalariadas e outras atividades realizadas no meio rural, paralelas ao trabalho assalariado. Essas atividades serão definidas ao longo das narrativas devido às particularidades de cada caso. Em outras palavras, busca-se apresentar algumas notas etnográficas sobre a importância para a população de uma pequena cidade pampeana das atividades paralelas ao emprego formal; consumadamente essas "atividades outras" são relacionadas às lidas do campo, por meio da pecuária ou algo muito similar. Procura-se seguir de perto as categorias nativas que definem o que é considerado especificamente trabalho sem deixar de observar suas fluências, contradições e as possíveis ocultações 
presentes nas narrativas. Como sugere Florence Weber (2009, p. 29), olhar e escutar ao invés de interrogar pode ser uma estratégia para que o pesquisador não somente possa ouvir as classificações nativas, mas também para que evite receber respostas que seriam o espelho de suas questões.

Observa-se, nesse universo das atividades paralelas ao emprego, a importância que tem certo saber fazer, que ultrapassa de certa maneira a profissão "oficial" dos sujeitos habitantes desse território designado como pampa. Não se pretende descrever aqui todos os detalhes de como se organizam e são pensadas essas práticas, no entanto, é possivel aproximar, em alguma medida, isso que se nomeia de "saber fazer" com o conceito de habitus, pois se trata de saberes, ofícios, tarefas e atividades implícitas ao trabalhador rural gaúcho.

Esse saber fazer é reconhecido e designado pelos nativos como um saber campeiro, o detentor desse conhecimento é o sujeito nomeado campeiro, aquele que traz o conhecimento das lidas com os animais e das práticas no campo. Ele é ainda reconhecido por influências recíprocas do estilo de vida argentino e uruguaio no que diz respeito ao envolvimento por um mesmo sentimento de pertença à cultura gaúcha, a memórias, a ideias e a valores de um modo de vida e de trabalho, marcadamente ligado à pecuária extensiva e aos elementos constitutivos desse universo, como o cavalo, as vestimentas, a paisagem, a música, entre outros.

A propósito das recentes discussões sobre a origem do gaúcho ${ }^{1}$, é importante deixar claro que não se trata aqui de construir qualquer tipologia ou caracterização essencializada do gaúcho, muito pelo contrário; espera-se descrever as práticas sociais que são comuns nesse espaço para então reconhecê-las como experiências coletivas que permitiram narrativas individuais que são constitutivas desse estilo de vida e, principalmente, de formas de trabalho.

Ao considerar as trajetórias de vida de uma parcela dos trabalhadores urbanos da cidade gaúcha de Herval, observa-se que a origem rural é muito próxima: se não os próprios são recém-chegados ao meio urbano ou são seus pais e avós que têm um passado vivido no meio rural. A memória dessa existência dificilmente se dissolve plenamen- 
te mediante as novas experiências urbanas, pelo contrário, o que se pode observar é a incidência e a ressignificação dos costumes rurais para o cotidiano urbano. São as práticas e os costumes advindos da campanha que incidem sobre as práticas e os costumes urbanos, com raras exceções do inverso.

O trabalho e seu significado conformam muitas vezes a cultura de uma localidade e, por consequência, as transformações e a modernização no processo produtivo e na paisagem são, constantemente, ameaças a determinadas profissões e também à própria geografia do $\operatorname{lugar}^{2}$. Leite Lopes (2011, p. 596), em suas pesquisas, aponta para a forte ligação entre a memória individual e a memória histórica, chamando atenção para algo semelhante ao que se pode observar, ou seja, que memórias individuais e históricas passam pela memória do próprio grupo e se manifestam nas formas de dominação estabelecidas localmente e também nas formas de resistências desses grupos.

Nesse sentido, trata-se também de uma tentativa de ver, nessa memória conformada por um estilo de vida rural, aquilo que é proposto por Silveira e Buendía (2011) sobre o pastoreio na Espanha, conhecido como transumância ${ }^{3}$, ou seja, uma tentativa de que, por meio de especificidades culturais, certas atividades sejam vistas como um patrimônio imaterial. Conforme os autores Silveira e Buendía, (2011, p. 146), pode-se pensar "[...] a noção de patrimônio para fazer referência aos bens culturais considerados representativos de uma dada sociedade ou de um determinado momento histórico".

O desenraizamento provocado pelo processo migratório para os grandes centros urbanos - e não apenas para eles - transforma muitos saberes e ofícios em realidades ameaçadas de desaparecimento além de promover rupturas com relações comunitárias (Frochtengarten, 2005). Apesar disso, esses deslocamentos podem ser pensados do ponto de vista da contingência, ou seja, de proporcionarem o ressurgimento de novos significados para o universo das relações de trabalho sem, no entanto, serem despregadas do passado, daquilo que é informado pela memória coletiva. Observa-se, por exemplo, o caso de um antigo peão campeiro: senhor Juvêncio perdeu seu emprego porque a terra da antiga estância foi vendida para as empresas de reflorestamento, ele 
tornou-se então guarda-noturno no centro de Herval. Essa interrupção de um determinado tipo de emprego não significa absolutamente o desprendimento de seu estilo de vida, envolto em costumes advindos do meio rural que ele sempre conheceu. Ou seja, ele tem não apenas o hábito de se vestir de bombacha e bota, além do poncho, nas noites frias, para realizar a ronda noturna no quarteirão das casas na parte de "cima" da cidade, como mantém, em um pequeno pátio, o seu cavalo, para eventualmente "dar umas encilhadas" e não perder o costume. Casualmente pode também ajudar algum amigo que tenha "um pedaço de campo" a realizar qualquer lida campeira para qual seja convidado 4 . Senhor Juvêncio conta que se sente menos longe das lidas do campo ao ter seu cavalo próximo, apesar de seu emprego não ter qualquer relação com andar a cavalo.

Desse modo, a atividade campeira não entra no cômputo de trabalho propriamente, todavia, não deixa de ser uma atividade, um ofício. Melhor explicando, pelo gosto de fazê-la, que está implícito na atividade campeira, para muitos daqueles que são chamados para realizá-la, a atividade é intuída por outra percepção pelos campeiros que, no geral, não percebem como relação formal de trabalho, de diarista ou de assalariamento. Não se quer com isso que essas relações trabalhistas não existam e até mesmo já sejam predominantes no pampa, mas, sobretudo, observa-se que atividades como um convite para uma lida campeira ou para laçar e marcar o gado bovino podem ser pensadas mais do ponto de vista da reciprocidade. Exemplo bastante comum disso é que, quando um pequeno criador de vacas ou ovelhas chama algum de seus conhecidos, que não têm terras, para ajudá-lo a realizar alguma lida campeira, dificilmente a remuneração pelo dia de ajuda é em forma de dinheiro, mas sim através de algum tipo de benefício como um pedaço de carne de ovelha (oferta bastante comum na região), um pastoreio para o cavalo, permissão para cortar lenha na propriedade, ou algum outro tipo de regalo.

A pequena propriedade rural e/ou a realização de algum trabalho eventual no campo - uma changa, como chamam - não tem como objetivo primeiro ocasionar rendimentos monetários. Essa é uma característica interessante para se pensar as atividades paralelas, pois 
elas são encarregadas de outras formas de benefício (fundamentalmente lenha, leite e carne, eventualmente a venda de algum ovino ou bovino por eventualidades de ordem econômica) tal como o bricole para os operários de Weber (2010) se diferencia do assalariamento5. Em alguns casos, observou-se que parte do trabalho assalariado urbano é reservado para a possível compra de uma propriedade rural, mesmo que, ao adquiri-la, o trabalho nesta não produza rendimento suficiente para que os trabalhadores possam abandonar o emprego.

Observa-se ainda que, mesmo adquirindo ou arrendando uma propriedade rural, não se encontra nenhum dos trabalhadores de Herval que adquirindo à terra tenha abandonado por completo o emprego urbano assalariado. Afinal, o "pra fora" (expressão ambivalente, serve para definir a propriedade rural e o ato de ir para a mesma) de cada um não tem atribuição de mudança ou rupturas, apenas de continuidade do estilo de vida que era muitas vezes praticado em propriedade de outros.

\section{Quem são os Trabalhadores do Meio Rural Conhecidos como Gaúchos?}

A princípio, faz-se necessário apresentar as diferentes definições nativas da expressão "gaúcho" para, a seguir, elencar as definições que aparecem na literatura afim. Na linguagem nativa há uma diferença entre gaúcho e gaúcho, mesmo que a palavra usada seja a mesma. Melhor explicando, ao nomear um morador do Rio Grande do Sul o termo usado também é "gaúcho", no entanto, essa expressão é mais comumente usada na região para designar um morador da campanha, alguém que se ocupe e conheça as lidas do campo. Ocorrem ainda distinções mesmo dentro dessa última definição: chama-se de "gaúcho" ou ainda de "bem gaúcho", "campeiro" aquele indivíduo que é dotado do "saber fazer" do trabalho da pecuária já referidos, todavia, também são chamados de gaúcho os eventuais participantes de festas de rodeio, estes normalmente permanecem paramentados com vestes gauchescas, mas não são considerados como "campeiros", porque, frequentemente, desconhecem a realidade do trabalho no campo. 
Entretanto, não se trata de encontrar uma versão homogênea e acabada do estilo de vida que caracteriza o gaúcho, sequer de imaginar que qualquer definição aqui sugerida encerre outras modalidades de experiências no interior da cultura dita gaúcha, ao contrário, buscase uma aproximação entre a história e a antropologia para abordar aspectos históricos e suas reinvenções nativas (Comarrof; Comarrof, 2010). Tratar a cultura gaúcha à maneira das proposições do nativo desta pesquisa - o gaúcho - e suas narrativas como objeto etnográfico também contaria pouco se não se soubesse como traduzir isso em um processo que dessencialização da cultura. O que se condiz, etnograficamente, foram sim trabalhadores sujeitos às forças e intensidades de uma determinada cultura à qual eles mesmos reinventam constantemente (Wagner, 2010). Em tal contexto, pode-se indagar: historicamente, como surge esse tipo que sintetiza uma época, e que para muitos, apesar do trânsito dos tempos, ainda permanece vivo no campo da memória, da tradição e de certos modus vivendis contemporâneos e antigos?

\section{Observações Etnográficas sobre as Noções de Trabalho e de Emprego para os "Gaúchos"}

O tratamento etnográfico que será concedido ao tema parte de observações esparsas, que, ao longo dos últimos cinco anos, tem sido realizado sobre os estilos de vida e as formas de trabalho de uma parcela dos habitantes da cidade de Herval. O município de Herval, situado na região sul, bioma pampa, a fronteira com o Uruguai é o lócus privilegiado deste trabalho de pesquisa por ser nesta cidade que se tem a nossa própria experiência de vida nas fazendas e estâncias aí localizadas. O contato semanal durante muitos anos com os trabalhadores rurais, observando seus modos de vida, os costumes, o cotidiano de trabalho e os momentos de lazer e diversão serviram de mote para que se voltasse o olhar para o passado descrito na literatura e fizesse um contraponto com o que se percebe no presente . $^{6}$

A preocupação deste artigo aproxima-se daquilo que Florence Weber (2010) etnografou em uma cidade operária francesa, ou seja, como se compreendem as atividades paralelas ao trabalho formal, ou, 
que lugar esse "trabalho fora do trabalho" ocupa na vida das pessoas com ele envolvidas? Neste caso, procura-se etnografar - pois ainda se está construindo a pesquisa - as relações de trabalho em que os sujeitos envolvidos dividem seu tempo entre o trabalho urbano, assalariado e atividades conhecidas como ir "pra fora", ou seja, para o meio rural. O quanto essa segunda atividade - que envolve a terra, as lidas com o cavalo e com os animais domésticos, enfim, como foi colocado acima esse misto de trabalho e aventura - faz-se presente na trajetória dos moradores da cidade, marcando o ritmo do trabalho assalariado e da própria cidadezinha que se esvazia nos fins de semanas por que boa parte da população possui um "pra fora"? Interessa, portanto, tentar entender esse evento do possuir e ir "pra fora", afinal esse é um evento que aparece de forma incisiva nas narrativas sobre o trabalho no pampa.

As trajetórias desses trabalhadores revelam as diferentes experiências e temporalidades envolvidas em suas definições de trabalho: as lidas campeiras, como normalmente designam as diversas tarefas que compõem o metier do gaúcho; tarefas que envolvem fundamentalmente as destrezas em cima do cavalo, com o laço e o trato com o gado bovino e ovino. Aquele que sabe realizar as lidas campeiras é, por aqui, definido como campeiro, gaúcho, bem gaúcho, da campanha. Essas definições anunciam referências e categorias informadas pela memória do trabalho nas fazendas e estâncias da região do pampa gaúcho. Por conseguinte, foi preciso atentar o grau de intensidade que a memória e as reinvenções das formas de trabalho compõem as narrativas dos trabalhadores gaúchos com o quais se convive. O sentimento de pertencimento a um determinado lugar, fato que habita intensamente a memória, convive no interior desses trabalhadores com o desejo de retorno à terra.

São dois mundos - o rural e o urbano - e duas temporalidades - a memória e as recriações contemporâneas do trabalho - que se interseccionam e revelam não um antagonismo entre si, sobretudo, anunciam uma relação de complementaridade por que esses sujeitos, ao adquirem sua pequena gleba, acabam se inserindo em um terreno simbólico no qual assumem outra visibilidade na cidade, já que não contam apenas por suas profissões urbanas, mas incorporam os sentidos do ser proprietário agrário. 
Procura-se entender não apenas esse cruzamento que se dá entre vida rural e trabalho urbano, mas ainda, saber como isso é vivido no campo da produtividade, e como determinado estilo de administração agrícola marca os resultados econômicos e sociais do lugar. ${ }^{7}$ Pode-se observar que desde sempre a população de Herval vai "pra fora" nos fim de semanas ou sempre que for possível, mesmo que o "fora" seja de um parente (fundamentalmente sogros ou pais) ou, mais raramente, alguém conhecido. Nos últimos anos muitos trabalhadores urbanos obtiveram uma pequena propriedade agrícola, esse aumento do número de pequenos proprietários rurais explica-se pelo programa, instituído pelo governo Fernando Henrique Cardoso chamado Banco da Terra, onde muitos trabalhadores (pedreiros, mecânicos, professores, policiais militares, bancários) tiveram por fim realizado o sonho da propriedade rural.

O interessante de observar são as reapropriações feitas pelos novos proprietários para a política da terra criada pelo governo. Em outras palavras, se essa política visava reconstruir a ordem agrária no pampa gaúcho, a partir de um viés de inserção dos novos proprietários em um circuito produtivo voltado ao abastecimento agrícola dos centros urbanos, nota-se nas pesquisas um processo de quase solapamento da proposta da dita política pelos novos proprietários, pois esses a partir da aquisição do lote, ao redor de 25 hectares, buscam realizar em sua terra um modo de vida e trabalho ligado à grande e à média propriedade pecuarista, muito comum na cidade de Herval.

Como já foi dito, interessa aqui as possibilidades narrativas dessas vidas de tautocronias de mundos interseccionados: o da cidade, o da ocupação, lugar de onde tiram o dinheiro do trabalho no campo, onde o lucro não necessariamente é o mais importante, mas os cuidados, as lidas, a aventura de atirar laço, domar um cavalo, enfim, arranjos que parecem aproximá-los dessa espécie de paixão pela lida do campo. Na voz dos sujeitos, o emprego é um recurso para chegar à propriedade da terra e, sobretudo, esses modos de vida que não se separam, muito pelo contrário, estão amalgamados de tal forma que muitos trabalhadores possuem um cavalo no pátio de suas casas no centro da cidade esperando, talvez, o momento de poder levá-lo "pra fora". 
É possível trazer aqui inúmeros exemplos que surgiram na pesquisa seja em momentos "formais" de trabalho de campo ou observações feitas no cotidiano, no convívio com amigos e trabalhadores conhecidos, afinal também se frequenta como moradores o mundo hervalense. Portanto, no necessário recorte a ser feito, opta-se por trazer algumas histórias que se acompanha mais de perto, como o caso de senhor Beto, o pedreiro.

Foi possível conhecer o senhor Beto em 2009 ao contratá-lo para um serviço de pedreiro e, a partir de então, manteve-se contato quase cotidiano durante cerca de um ano e meio. O senhor Beto residia na cidade até 2010, ano em que obteve um financiamento do Banco da Terra e pode então realizar o sonho que acalentava há anos, motivo para que trabalhasse duro como pedreiro, inclusive aos fins de semana. Na frente da casa do senhor Beto, situada na parte baixa da cidade, (que conforma em sua geografia uma separação para além de topografia, mas também de condição econômica, sendo o Herval de cima das classes mais abastadas e o "de baixo" das famílias de menor poder aquisitivo) quase sempre tinha um cavalo atado na sombra das árvores que ficavam na beira da calçada. Um fato corriqueiro: um cavalo no pátio, na calçada, uma vaca no terreno baldio, uma ovelha na beira da casa, figuras comuns na paisagem local. Essa é a forma possível de continuar vinculado ao mundo rural em uma condição ainda de não proprietário ${ }^{8}$.

O serviço de pedreiro do senhor Beto era realizado por empreitadas - um acordo sobre o preço total da obra, e não como diarista, - o trabalho era realizado como uma espécie de "mutirão" em família, pois seus serventes eram o filho e o sobrinho. Esse tipo de "contrato" de trabalho lhe permitia aceitar outros pequenos serviços de pedreiro nos fins de semana, mais curtos, ligados a consertos e reformas, permitindo um acréscimo no seu ganho. Antes de ser pedreiro, o senhor Beto trabalhou como peão nas fazendas da região realizando todo tipo de trabalho - esquilava e carneava ovelhas, recorria o gado, domava, tirava leite, laçava, curava os animais, etc. - e apenas deixou esse emprego por que a retribuição era muito baixa e sem nenhum direito garantido, nada de carteira assinada, previdência social, a única coisa que havia 
era a lealdade patronal e isso pressupõe uma dependência impeditiva de exigências salariais ou de melhores condições de trabalho.

Cansado desse mundo, o senhor Beto resolve começar a vida de pedreiro, como um meio que, além de garantir seu sustento e da família, permitisse um rendimento extra para fazer algum investimento, no caso um pedaço, como dizia: pedaçinho que fosse de algum campinho. Assim, depois de longos anos de árduo trabalho como pedreiro, sem muitos finais de semanas, nos feriados nem pensava em parar de $p e-$ dreriar, com todo o esforço familiar, o senhor Beto consegue adquirir por meio de um longo financiamento do Banco da Terra cerca de 20 hectares.

Bem, o que é interessante nesse caso, assim como, em tantos outros, é que o senhor Beto não pensa em nenhum momento deixar de ser pedreiro para ser agricultor, afinal, na região sul, com essa quantia de terras que comprou dificilmente conseguirá manter-se e, menos ainda, com o modelo que pretende adotar na propriedade: a criação de gado, ovelhas e cavalos. Ocorre que agora, ao invés de trabalhar aos fins de semanas para ter uma renda extra, seu Beto passa seus finais de semana "no campinho" como chama carinhosamente. Ali continua trabalhando pesado, mas agora trabalha para si mesmo. A última vez em que houve conversa, estava ele próprio fazendo a cerca de arame que demarcava os limites da propriedade, o que nos contou com um grande orgulho. Seu filho, que antes mantinha os cavalos atados na frente da casa da cidade, agora fica mais tempo "pra fora" cuidando dos animais.

Observa-se que, recentemente, o "estilo de vida rural" tem passado por algumas mudanças na região; o estilo tradicional de vestimentas, montarias e encilhas tem perdido espaço para outras maneiras de montaria e de raça dos cavalos procuram sempre uma aproximação com os cavalos da raça crioula, cujos animais puros de sangue apenas os grandes proprietários conseguem adquirir.

Um dos programas prediletos do senhor Beto, assistido pela televisão, são as mostras e feiras no setor do agronegócio, como Exposição Internacional de Animais, Máquinas, Implementos e Produtos Agropecuários - EXPOINTER, realizada todos os anos em Esteio, região 
metropolitana de Porto Alegre. Nessas feiras são as grandes fazendas que expõem seus produtos e animais, mas chama especial atenção do senhor Beto os cavalos da raça crioula. Os participantes apresentam os animais com alto nível de preparo e refinamento genético, que necessitam ainda de certificados e mapeamentos genealógicos, questões que restringem muito a aquisição de um desses cavalos crioulos por pequenos e médios proprietários. Contudo, especialmente para as gerações mais jovens, o estilo de montar e de escolher um animal para montaria segue uma aproximação ao 'modelo' que tem sido divulgado nos últimos anos pela Expointer ou por outras feiras e mostras realizadas pelos grandes criadores de cavalos crioulos.

Atualmente, o senhor Beto se sente bastante realizado com a propriedade e sua vida volta-se praticamente para as melhorias no "seu pra fora", conta que frequenta quase sempre os remates de gado para tentar algum "negocinho, uma pechincha", e conversar com os demais, no entanto, todo tempo que tem de sobra vai "pra fora". Enfim, seu cotidiano agora é mais do que nunca atravessado pelo mundo da campanha, do campo, das lidas a cavalo, mas sem deixar, no entanto, de ganhar seu sustento como pedreiro, coisas que são para ele, absolutamente, conciliáveis.

Não há ruptura ou saída de um universo para o outro, eles se complementam, transigem e informam intensamente o aparato simbólico que institui modelos e estilos para a sociabilidade local. Daniel, outro conhecido de longa data trabalha em um escritório contábil na cidade há cerca de 20 anos, seu horário no escritório é das 8 h da manhã às $11 \mathrm{~h} 30$ min e no período da tarde das $13 \mathrm{~h} 30$ min às $17 \mathrm{~h}$, no verão do sul esse horário da tarde permite que durante a semana possa ir "pra fora" algumas vezes. O escritório não abre aos sábados, permitindo a Daniel ir ao final de todas as sextas-feiras para sua propriedade rural, situada a cerca de $20 \mathrm{~km}$ do centro de Herval. Diferentemente do senhor Beto, Daniel não comprou a terra através de financiamento público, mas herdou de sua família nos anos 2000. Anterior a essa data, quando a terra ainda era de seu pai, ia da mesma forma para fora onde mantinha seus cavalos para camperiar ${ }^{9}$ e para participar de cavalgadas e rodeios promovidos pelo Centro de Tradições Gaúchas (CTG). Atualmente diz 
que deixou de lado essas festas e cuida dos cavalos apenas pelo gosto de camperiar e "dar boia pra bicharada".

Sua esposa Maria trabalha como funcionária pública na prefeitura municipal e ambos arranjam seus horários de forma que possam compartir o trabalho no escritório e na prefeitura com as idas "pra fora". Durante o horário comercial da semana Daniel permanece no escritório e, quando possível, ao final do dia vai "pra fora", especialmente no verão quando os dias são mais longos e os animais precisam de mais cuidado. Apesar de participar com certa frequência dos remates rurais, de vender ou comprar alguma rês e obter algum rendimento na venda da lã das ovelhas no período de fim da primavera, a atividade econômica da propriedade rural não é o que garante o sustento de Daniel e Maria, uma vez que percebem os ganhos daí provenientes como um extra, um acréscimo aos salários urbanos. De modo algum, isso significa que eles não trabalhem duro na propriedade rural, que não cuidem do gado, da casa, das mangueiras, tenham lenha, carne e leite trazidos "de fora", no entanto, da mesma forma que o senhor Beto, dentro do contexto rural do pampa onde predomina a pecuária extensiva, é muito difícil para um pequeno e até mesmo um médio proprietário rural obter rendimento monetário compatível com os atuais padrões de consumo.

O que de fato assegura o rendimento monetário é o emprego assalariado urbano no caso de quem tem um emprego ou o trabalho como autônomo como seu Beto que tem a profissão de pedreiro. Entretanto, há ainda aqueles que têm uma pequena empresa na cidade, contudo, não deixam de ter o seu "pra fora". É possível tomar o senhor Luís como exemplo de outros casos análogos de pequeno empresário urbano e proprietário rural. O senhor Luis tem uma serralheria na garagem de sua casa em uma rua não muito distante do centro da cidade. Reconhecido por ser "o mais inteligente" dos ferreiros locais, o senhor Luis não começou há muito tempo o ofício de forjar ferros e construir grades, portas, arrumar arados entre outras inúmeras atividades que faz na oficina. Antes de vir para cidade, nos anos de 1980 trabalhava na terra da família, campereava com o pai e um dos irmãos que também "gosta das lidas pra fora" e complementava sua renda prestando o 
serviço de inseminador de ovelhas para um vizinho estancieiro. Quando casou e seus filhos ficaram em idade de estudar, sua esposa veio primeiramente para cidade e alguns poucos anos depois o senhor Luis também se mudou. Quando perguntou-se por que deixou de morar no campo, o argumento de senhor Luis é a dificuldade de obter dinheiro para sustentar à família na cidade: "a campanha é muito boa, lá a gente tem tudo, mas para se manter é muito difícil, para sustentar filho estudando precisei pegar uns serviços de pedreiro aqui, era meia colher, mas dava. Depois, o Odilon me ofereceu a serralheria e me ensinou o serviço".

Atualmente sustenta-se dos rendimentos do trabalho de serralheiro, conta que a vida esta mais folgada por que já pagou o ensino para os filhos e sempre tem pedidos de serviços em ferro. No entanto, não é muito fácil encontrar o senhor Luis na oficina. Diversas vezes buscou-se ele para realizar um serviço ou conversar e o portão estava cerrado. A vizinha explica: foi "pra fora". o senhor Luis tem um "pra fora" situado a cerca de $8 \mathrm{~km}$ do centro de Herval e possui 41 hectares que herdou da família e arrenda outros 35 de um de seus irmãos que, como diz "nunca foi da coisa, nunca foi dado à campanha, desde guri. A gente vê desde cedo quem vai ser da coisa, tá na pessoa, parece!" Conta ainda que divide as lidas campeiras com outro irmão, que o rendimento é quase nenhum, muito pouco "ainda mais que é pra dois" e, além disso, muitas vezes para pagar o arrendamento precisa tirar do bolso (entende-se que seja dos rendimentos de serralheiro) por que não obtém o suficiente na propriedade rural. Indagado por que mantém e vai "pra fora", o senhor Luis nos explica com um grande estupefação, dando a entender que se conhece bem o porquê: "ora bah! Por que se gosta, não se sabe viver sem. É o gosto, me criei na campanha, tá na gente, no sangue parece até. Às vezes vou final de semana e trabalho mais que toda semana e volto descansado, com a cabeça livre!"

É possível observar que alguns elementos perpassam pelas descrições apresentadas, entre eles é importante chamar a atenção para aquilo que é definido como "gosto", o prazer de ir "pra fora". Em conversas informais com esses trabalhadores nota-se certa preponderância em afirmarem que através da propriedade rural não é possível obter rendimentos e seu sentido último é o prazer, o costume de camperiar. 
Não nos cabe aqui, e sequer é essa nossa intenção, questionar a importância atribuída aos nativos à realização pessoal, pelo contrário, ao observar suas narrativas e memórias busca-se apenas desvelar outros meios e arranjos menos explícitos, mas que se interlaçam na definição de trabalho e rendimento. Em outras palavras, é possível considerar que se tem um trabalho (assalariado/urbano) que permite a existência de outra forma de trabalho (camperiar/rural), cujas narrativas atribuem, ao primeiro, o sentido de necessidade e, ao segundo, de compensação.

Todavia, algumas questões podem ser levantadas, menos para explicar-se e mais para discutir-se o intrincado jogo das relações de trabalho locais. Se os trabalhadores de Herval compreendem o trabalho realizado no meio rural como não suficiente do ponto de vista da geração de renda monetária e precisam de outra fonte, igualmente percebem que o trabalho rural ajuda a custear certas despesas e alguns confortos que não poderiam arcar sem ele. Como já foi dito, em situações de emergência, fundamentalmente de doenças ou no caso da precisão imediata de adquirir algum bem, é da produção rural que o recurso é obtido através, na maioria dos casos, da venda de algum animal. Afora isso é preciso creditar ao trabalho "pra fora" vários produtos que fazem parte dos usos familiares tais como o leite, a carne e a lenha, produtos que não seriam tão abundantes para esses trabalhadores caso não fossem provenientes do próprio trabalho. No entanto, tem outro elemento bastante significativo e, sobretudo, submerso, que se anuncia apenas nas entrelinhas dos discursos quando este revela assimetrias sociais entre quem de fato tem como ir "pra fora", é proprietário de terra e aqueles despossuídos dessa possibilidade.

Pode-se então perceber que o trabalho rural não é contabilizado propriamente, todavia tem uma função importante na economia doméstica e na construção dos lugares sociais, situando-se na verdade para além do simples "gosto", antes, aliado a este, é o esteio desse estilo de vida onde trabalho rural/urbano passam a existir intensamente imiscuídos pelas transversalidades entre memória, gosto e contingências. Sobretudo, percebe-se que, a outra parte da vida desses trabalhadores urbanos, constituída no "pra fora", revela uma tentativa de edificação de sentido para sua existência, a partir de um lugar, no 
qual eles, fundamentalmente os homens, se encontram de alguma forma mais senhores de si. Em última instância, parece tratar-se da constituição de um lugar, no qual, se leva uma vida completa, não instrumentalizada pelo mundo do trabalho urbano.

Esses homens buscam na terra uma relação sem fraturas, sem as mediações e as contradições do mundo urbano, no qual os conflitos, as dificuldades sociais, a limitação de uma vida precária, como empregado ou como pequeno empreendedor se fazem presentes. Essa busca pela terra não é a busca por uma solução econômica ou por uma mentalidade organizada em cálculos de custo e beneficio, é, sobretudo, a busca de uma satisfação subjetiva, pessoal. O que se observa é uma tentativa de criação de um espaço de liberdade e autenticidade por parte desses sujeitos, já que a terra, a propriedade agrária, lhes proporciona reconhecimento e sentido existencial, coisas que o mundo urbano não lhe proporciona. Talvez o poeta Nejar pressagie bem: " $O$ Campeador é o que não morre no homem".

\section{Notas:}

1 Referimo-nos aos dois artigos publicados na revista Horizontes Antropológicos, em 2012, pelos autores Kent e Santos e a réplica de Bortolini (2012) conforme referenciada.

2 Eudes Leite (2012) observa impacto semelhante provocado pela modernização no campo nas fazendas de gado no Pantanal Mato-grossense.

3 A transumância se caracteriza pelo deslocamento dos pastores e rebanhos por longas distâncias e tem sido considerada uma atividade fadada ao desaparecimento na Europa, em razão do número cada vez mais reduzido de pastores. (Silveira; Buendía, 2011)

4 Preferiu-se usar a expressão "pedaço de campo" ao termo casa, chácara ou sítio não apenas por ser esta ser a expressão nativa mais usual, como também por que as duas últimas não são muito bem vistas, ao significarem algo mais próximo à agricultura e ao descanso respectivamente, do que ao trabalho semelhante ao da pecuária extensiva. Para uma definição de casa e sítio camponês ver Woortmann e Woortmann (1997).

5 Bricole é uma das formas da atividade paralela ao emprego na fábrica realizada pelos operários franceses pesquisados por Weber (2010). A bricole tem como princípio o gosto pela atividade, o trabalho efetuado para si próprio.

6 Uma nota sobre os autores deste artigo: um de nós convive praticamente ao longo de toda sua vida com trabalhadores rurais da região sul, especificamente de Herval/RS, e o outro autor convive com os trabalhadores há cerca de dez ou 11 anos, portanto, sendo a pesquisa parte deste convívio.

7 A relação entre situação sociopolítica dos moradores de uma comunidade rural e a criação de animais pode ser encontrada no artigo de Jérémy Deturche (2012). 
8 Usa-se aqui a expressão "não proprietário" ao invés de sem terra por que dentro desse universo cultural mesmo os "sem terras" locais não gostavam de assim serem reconhecidos, pelo contrário, para eles, no geral, os agricultores sem terras vinculados ao MST não eram bem vistos, chegavam mesmo a ser considerados pelos não proprietários, como "invasores", pessoas que "ganharam a terra de mão beijada" entre outras definições depreciativas.

9 Preferimos manter a expressão nativa "camperiar" ao invés de campear.

\section{Referências}

BORTOLINI, Maria Cátira. Resposta ao trabalho de Kent e Santos: os charruas vivem nos Gaúchos: a vida social de uma pesquisa de resgate genético de uma etnia indígena extinta no Sul do Brasil, Porto Alegre. Horizontes Antropológicos, Porto Alegre, v. 18, n. 37, p. 373-378, jan.-jun., p. 373-378, 2012.

CARDOSO, Heloisa Helena Pacheco. Narrativas de um candango em Brasília. Revista Brasileira de História, São Paulo, v. 24, n. 47, p.163-180, 2004.

COMARROF, Jean; COMARROF, John. Etnografia e imaginação história. Tradução Iracema Dulley e Olívia Janequine. Revista Proa, Campinas, n. 2, v. $1,2010$.

DETURCHE, Jeremy. As vacas da discórdia: gestão e raça do rebanho entre os criadores de vacas montbéliardes na Haute-Savoie, França. Revista Ilha, Florianópolis, v. 14, n. 2, p. 139-169, jul.- dez. 2012.

FAVRET-SAADA, Jeanne. Les mots, la mort, les sorts. Paris: Gallimard, 1977.

FAVRET-SAADA, Jeanne. Ser afetado. Tradução Paula de Siqueira Lopes. Cadernos de Campo, São Paulo, n. 13, p. 155-161, 2005.

FERREIRA, Letícia de Faria; GONÇALVES, Jussemar Weiss. Trabalho e Memória na Campanha Gaúcha. In: COSTA, Benhur Pinós da; QUOSS, João Henrique; DICKEL, Mara Eliana Graeff (Org.) A sustentabilidade da Região da Campanha-RS: práticas e teorias a respeito das relações entre ambiente, sociedade, cultura e políticas públicas. Santa Maria. Universidade Federal de Santa Maria, Programa de Pós-Graduação em Geografia e Geociências, Departamento de Geociências, 2010. p. 129-139. (e-book)

FERREIRA, Letícia de Faria; GONÇALVES, Jussemar Weiss. Memória Rural, Vida Urbana. In: I ENCONTRO SUL-AMERICANO DE ESTUDOS AGRÁRIOS. Rio de Janeiro: UNIRIO - UFRRJ, 12 a 15 de setembro de 2011. Anais... Rio de Janeiro, 2011. (CD-ROM)

- O Campo e o Trabalho: a memória como resistência. In: $26^{\circ}$ REUNIÃO BRASILEIRA DE ANTROPOLOGIA - RBA, GT: desafios antropológicos do mundo do trabalho na cidade e no campo. São Paulo, 2012. Anais... São Paulo, 2012. 
FROCHTENGARTEN, Fernando. A memória oral no mundo contemporâneo. Estudo Avançados, São Paulo, v. 19, n. 55, p. 367-376, 2005.

GONÇALVES, Jussemar Weiss. Gaúchos e Gaúchos: com a fronteira na alma. In: I CONGRESSO INTERNACIONAL DE TURISMO: TURISMO, HISTÓRIA E CULTURA. Santa Vitória do Palmar: Universidade Federal de Rio Grande, 2010. Anais... Rio Grande do Sul, 2010.

ISABELLE, Arsène. Viagens ao Rio Grande do Sul. 1833-1834. Porto Alegre: Martins Livreiro, 1983.

KENT, Michael; SANTOS, Ricardo Ventura. Os charruas vivem nos Gaúchos: a vida social de uma pesquisa de resgate genético de uma etnia indígena extinta no Sul do Brasil. Horizontes Antropológicos, Porto Alegre, v. 18, n. 37, p. 341-372, jan.-jun. 2012.

- Genes, boleadeiras e abismos colossais: elementos para um diálogo entre genética e antropologia. Horizontes Antropológicos, Porto Alegre, v. 18, n. 37, p. 379-384, jan.-jun. 2012.

LEITE, Eudes Fernando. A vida e o trabalho: camaradas e peões em fazendas de gado no Pantanal. In: LEITE, Eudes Fernando; FERNANDES, Frederico. (Org.). Trânsitos da voz: estudos de oralidade e literatura. Londrina, Dourados: Eduel/Edufgd, 2012. v. 1, p. 163-188.

LEITE LOPES, José Sergio. Memória e transformação social: trabalhadores de cidades industriais. Mana, Rio de Janeiro, v. 17, n. 3, p. 583-606, dez. 2011.

NEJAR, Carlos. O Campeador e o vento. Porto Alegre: Sulina, 1966.

NORA, Pierre. Entre Memória e História: a problemática dos lugares. Projeto História: Revista do Programa de Estudos Pós-Graduados em História e do Departamento de História da PUC-SP. São Paulo, p. 5-16, 1981.

ORNELLAS, Manoelito de. A Gênese do gaúcho brasileiro. Rio de janeiro: MEC, 1956.

SAINT-HILAIRE, Auguste de. Viagens ao Rio Grande do Sul. Belo Horizonte: Itatiaia, 1968.

SILVEIRA, Luciana Braga; BUENDÍA, Mercedes Pardo. Da Invenção da tradição (ou de como os patrimônios nos inventam): notas sobre a patrimonialização do pastoreio na Espanha. Horizontes Antropológicos, Porto Alegre, ano 17, n. 36, p. 145-169, jul.-dez. 2011.

STRATHERN, Marilyn. Introduction: Rationales of Ownership. In: KALINOE, Lawrence; LEACH, James (Ed.). Rationales of ownership: transactions and claims to ownership in contemporary. Papua New Guinea, 2004. 
WAGNER, Roy. A invenção da cultura. São Paulo: Cosac \& Naify, 2010.

WEBER, Florence. Le travail-à-côté, étude d'ethnographie ouvrière. Paris: EHESS: INRA, 1989.

. A entrevista, a pesquisa e o íntimo, ou: por que censurar seu diário de campo? Horizontes Antropológicos, Porto Alegre, ano 15, n. 32, jul.-dez. p. 157-170, 2009.

. Trabalho fora do trabalho: uma etnografia das percepções. Rio de Janeiro: Garamond, 2009.

WOORTMANN, Ellen; WOORTMANN, Klass. O trabalho da terra: a lógica e a simbólica da lavoura camponesa. Brasília, DF: UnB, 1997.

Recebido em 05/06/2013

Aceito em 21/11/2013 